\title{
OPEM
}

www.opem.org

Oriental Pharmacy and Experimental Medicine 2008 8(4), 423-429

DOI 10.3742/OPEM.2008.8.4.423

\section{Anti-inflammatory and analgesic activities of methanol extract of Triphala - a poly herbal formulation}

\author{
D. Prabu $^{1, *}$, S. Kirubanandan ${ }^{2}$, K. Ponnudurai ${ }^{3}$, M. Nappinnai ${ }^{4}$,Alin J.S. Jinu ${ }^{5}$ and S. Renganathan ${ }^{6}$ \\ ${ }^{1}$ Department of Pharmacology, C.L.Baid Metha College of Pharmacy, Chennai 600 097, Tamilnadu, India; \\ ${ }^{2}$ Centre for Biotechnology, A.C. Technology, Anna University, Adyar, Chennai 600 025, Tamilnadu, India; \\ ${ }^{3}$ Department of Pharmacology, Nandini Nagar Mahavidyalaya College of Pharmacy, Nandini nagar, Nawabganj, \\ Gonda 271303, Uttarpradesh, India; ${ }^{4}$ Department of Pharmaceutics, C.L.Baid Metha College of Pharmacy, \\ Chennai 600 097, Tamilnadu, India; ${ }^{5}$ Department of Pharmacology, Vel's College of Pharmacy, Chennai 600117, \\ Tamilnadu, India; ${ }^{6}$ Department of Chemical Engineering, A.C.Technology, Anna University, Adyar, Chennai 600 \\ 025, Tamilnadu, India
}

Received for publication December 18, 2007; accepted May 07, 2008

\begin{abstract}
SUMMARY
Ayurveda, an ancient System of Indian Medicine, has recommended a number of drugs from indigenous plant sources for the treatment of inflammation. To evaluate the anti-inflammatory and analgesic activities of methanol extract of Triphala were investigated in Wister albino rats and mice. The methanol extract of Triphala were found to encompass substantial anti-inflammatory effect in acute and sub-acute models and analgesic effect. Animal models of carrageenan induced edema and cotton pellet induced granuloma in albino rats were used. Extract of $200 \mathrm{mg} / \mathrm{kg}$ shows significantly reduced paw edema. Analgesics activity of Triphala with $200 \mathrm{mg} / \mathrm{kg}$ shown by significant reduction of writhing. These report shows to support the use methanol extract of Triphala in relieving inflammation and pain.
\end{abstract}

Key words: Triphala; anti-inflammatory; analgesic; rat; mice

\section{INTRODUCTION}

Ayurveda, an ancient System of Indian Medicine, has recommended a number of drugs from indigenous plant sources for the treatment of inflammation. Hence, the majority of the populations continue to hold traditional medicines in high esteem. In recognizing this, the World Health Organization has called the attention of many

\footnotetext{
${ }^{*}$ Correspondence: D Prabu, Department of Pharmacology, C.L.Baid Metha College of Pharmacy, Chennai -600 097, Tamilnadu, India. Tel: +91- 9962461232; Fax: +91-44-24960151; E-mail: prabu.pharma@gmail.com
}

countries to the ever increasing interest of the public in the use of herbal medicines and encourages countries to identify and exploit those aspects of traditional medicine that provide safe and effective remedies.

Phyto-pharmaceuticals from medicinal plants are widely used in folk medicine of many countries to treat different inflammatory conditions and in particular, skin inflammations, broncho-inflammations and arthritis. A large portion of the world population, especially in developing countries depends on the traditional system of medicine for a variety of diseases. Several hundred genera are 
used medicinally, mainly as herbal preparations in the indigenous systems of medicine in different countries and are sources of very potent and powerful drugs which have stood the test of time and modern chemistry has not been able to replace most of them. The World Health Organization reported that $80 \%$ of the worlds population rely chiefly on traditional medicine and a major part of the traditional therapies involve the use of plant extracts or their active constituents (Farnsworth, 1984).

The exposure of the presence of natural products, viz. polyphenols, alkaloids, flavonoids and other secondary metabolites, in medicinal plants will provide a scientific justification for the popular use of them and serve as a guide which may help in the selection of the plants with antiinflammatory and analgesic activity. Polyphenols present in plant have ability to inhibit lipoxygenase dependent per oxidation and to quench reactive oxygen species in various diseases such as autoimmune disease, inflammation and arthritis (Nadkarni, 1976).

Triphala, a formulation of three herbs, Terminalia chebula, Phyllanthus emblica or Emblica officinalis and Terminalia bellerica has been described in the Ayurveda as a 'tridoshic rasayan', having balancing and rejuvenating effects on the three constitutional elements that govern human life i.e.vata, pitta and kapha by Charka (1,500 B.C.) in the Charaka Samihita (Sharma and Dash, 1998). In the Ayurveda, the word rasayana is a term used for a therapy that produces sturdiness of the body, the sense organs and the teeth prevent wrinkles in skin, graying of hair and promote the immune functions and intellect and render longevity to life (Sharma and Dash, 1998). Triphala is one of the important rasayana drugs commonly used in the Ayurvedic system of medicine. This is an anti-oxidant herbal formulation, that has been reported to treat anemia, jaundice, constipation, cough, asthma, fever, eye diseases, chronic ulcers, leucorrhoea, pyorrhea (Nadkarni, 1976) and also assists in the weight loss (Hashimoto and Nakajima, 1997).
Triphala and/or its individual plant constituents have been reported various pharmacological properties of antibacterial (Nadkarni, 1976), antifungal activity (Dutta et al., 1998), anti-cancer (Tokura and Kagawa 1995), anti-mutagenic (Rani et al., 1994), anti-allergic (Takagi and Sanashiro, 1996), antiviral activities (Valsaraj et al., 1997), cardio-tonic (Tariq et al., 1977), and hepatoprotective activities (Gulati et al., 1995). Triphala directly administered orally $1 \mathrm{~g} / \mathrm{kg} /$ body weight was reported to have anti-arthritic and anti-inflammatory activity (Rasool and Sabina, 2007). There is no specified extraction of Triphala for anti-inflammatory and analgesic activities. So, the present study was evaluated antiinflammatory and analgesic activities of the methanolic extract of Triphala.

\section{MATERIALS AND METHODS}

\section{Plant material and composition of the drug}

As the name indicates, Triphala (tri $=$ three, $\mathrm{phala}=$ fruits) is a mixture of fruits of three plants namely Terminalia chebula Retz. (Family Combretaceae), Terminalia bellerica (Gaertn.) Roxb. (Family Combretaceae) and Phyllanthus emblica Linn or Emblica officinalis Gaertn. (Euphorbiaceae) in powdered form by equal proportions (1:1:1).

\section{Chemicals and drugs}

Carrageenan (Sigma, USA) was used for induction of inflammation. Indomethacin (Recon, Bangalore, India) were used as the standard drugs. All other reagents were used analytical grade.

\section{Experimental animals}

Inbred colony of adult male wistar albino rats (170 - $200 \mathrm{~g}$ ) and male swiss albino mice 20 - $25 \mathrm{~g}$ were used for the pharmacological activities. They were kept in polypropylene cages at $25 \pm 2{ }^{\circ} \mathrm{C}$, with relative humidity $45-55 \%$ under $12 \mathrm{~h}: 12 \mathrm{~h}$ light and dark cycles. All the animals were acclimatized to the laboratory conditions for a week before use. They were fed with standard animal feed (Poultry 
Research Station, Tamilnadu Veterinary and animal Sciences University, Chennai, India.) and water ad libitum. The test extracts and the standard drugs were administered in the form of a suspension in water using $1 \%$ Tween $80 \%$ as suspending agent. The data were subjected to Statistical analysis by employing ANOVA, followed by Student's $t$-test; values with $p<0.05$ and $p<0.01$ were considered as statistically significant. All the pharmacological experimental protocols were approved by the Institutional animal ethics committee.

\section{Preparation of methanol extract of triphala}

$100 \mathrm{~g}$ of powder were extracted in $500 \mathrm{ml}$ of methanol by stirring overnight and centrifuged at room temperature. The supernatant was collected and evaporated using roto-vapour vacuum distillation apparatus till the volume was reduced to one fourth of the original. The yield of the methanol extract was $12.5 \%$. The concentrated extract was aliquoted in amber-colored bottles and kept in desiccators for further use.

\section{Phytochemical screening of methanol extract of Triphala}

Preliminary phytochemical screening of the plant extract using the standard methods of Trease and Evans (1989) gave positive tests for polyphenols and tannins.

\section{Carrageenan-induced edema test}

Paw edema was induced by injecting $0.1 \mathrm{ml}$ of carageenan dissolved in saline containing $1 \%$ Tween 80 into the sub plantar tissues of the left hind paw of each rat (Winter et al., 1962). The methanol extracts of Triphala (100 and $200 \mathrm{mg} / \mathrm{kg}$ ) was administered orally $30 \mathrm{~min}$ prior to carrageenan injection. The paw volume was measured at 60,120 , 180, $240 \mathrm{~min}$ by the mercury displacement method using a plethysmometer. The percentage inhibition of paw volume in drug treated group was compared with the control group. Indomethacin $(10 \mathrm{mg} / \mathrm{kg}$ of b.w, p.o.) was used as a reference standard.

\section{Cotton pellet induced granuloma}

Male wistar albino rats (170 - 200 g) were divided into 4 groups of 6 animals in each group. Cotton pellets weighing $10 \mathrm{mg} \pm 1 \mathrm{mg}$ were autoclaved and implanted subcutaneously into both sides of the groin region of each rat (D'Arcy et al., 1960), Group I served as control and received the vehicle. The methanol extract of Triphala at concentrations of $100,200 \mathrm{mg} / \mathrm{kg}$ was administered orally for Group II and III animals for 7 days. Group IV animals received indomethacin at a dose of $10 \mathrm{mg} /$ $\mathrm{kg}$ orally for same period. On the 8 th day the animals were sacrificed and the pellets together with the granuloma tissues were carefully removed, dried in an oven at $60^{\circ} \mathrm{C}$, weighed and compared with control.

\section{Acetic acid-induced writhing test}

One hour after receiving oral (p.o.) administration of the plant extract, reference substance or solvent to groups of 6 mice, each mouse was given intraperitoneally $0.6 \%$ aqueous solution of acetic acid ( $2 \mathrm{ml} / \mathrm{kg}$ body weight) (Franzotti et al., 2002). Immediately after the algic compound injection, each animal was placed in a transparent observation cage and the number of writhes per mouse was counted for $30 \mathrm{~min}$. The writhing activity consists of a contraction of the abdominal muscles together with a stretching of the hind limbs.

\section{RESULTS}

In the present phyto-chemical investigation, the methanol extract of Triphala contains tannins, polyphenols and flavanoids (Table 1).

Table 1. Phyotochemical investigation of MET

\begin{tabular}{cc}
\hline Test & Observations \\
\hline Tannins & Present \\
Flavonoids & Present \\
Cardiac glycosides & Absent \\
Saponins & Absent \\
Alkaloids & Absent \\
\hline
\end{tabular}




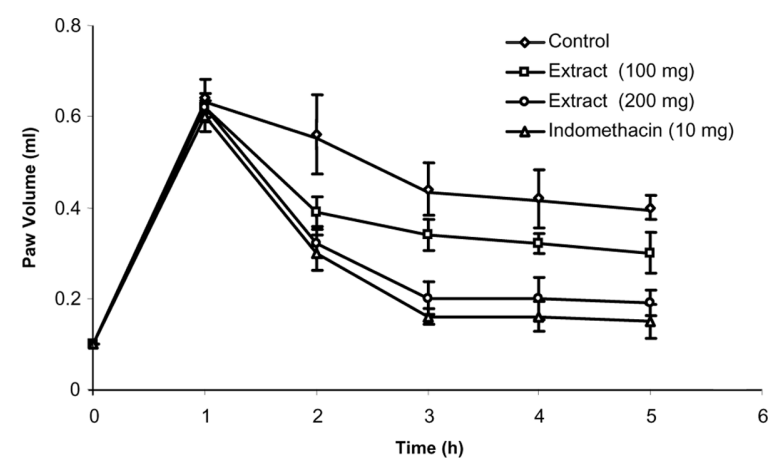

Fig. 1. Effect of MET on carrageenan induced paw edema test in rats.

\section{Anti-inflammatory activity}

The anti-inflammatory activity of methanol extract of Triphala (MET) was investigated at the dose of 100 and $200 \mathrm{mg} / \mathrm{kg}$, b.w. against acute paw edema induced by carrageenan, formalin and cotton pellet induced granuloma.

In the carrageenan-induced rat paw edema model, the MET produced significant $(p<0.01)$ anti-inflammatory activity and the results were comparable to that of indomethacin as a standard anti-inflammatory drug. The MET at the doses of
100 and $200 \mathrm{mg} / \mathrm{kg}$ of b.w. showed inhibition of $36.36 \%$ and $54.54 \%$ at the third hour after carrageenan injection whereas indomehacin shows $63 \%$ inhibition. The methanol extract of Triphala showed significant inhibitory effect on the edema formation (Fig. 1).

In cotton pellets induced granuloma model, the effects of MET and indomethacin on the proliferatitive phase of inflammation are summarised. It was seen that MET was responsible for anti-inflammatory effect, which would be calculated depending on the moist and dry weight of cotton pellets. According to these results, the anti-proliferate effects of MET at the dose of $200 \mathrm{mg} / \mathrm{kg}$ and indomethacin were investigated as $42.7 \%$ and $54.2 \%(p<0.05)$, on wet basis respectively. After they were dried, the antiproliferative effects were calculated on the basis of dry weight pellets, and the inhibitions of inflammation by MET $200 \mathrm{mg} / \mathrm{kg}$ and indomethacin were investigated as 50.1 and $59.4 \%(p<0.05)$, respectively (Table 2).

\section{Analgesic activity}

In acetic acid induced writhing in mice model,

Table 2. Effect of MET on cotton pellet induced granuloma in rats

\begin{tabular}{cccccc}
\hline Treatment & $\begin{array}{c}\text { Dose } \\
(\mathrm{mg} / \mathrm{kg})\end{array}$ & $\begin{array}{c}\text { Weight of cotton } \\
\text { pellet }^{\#}(\mathrm{mg})(\text { wet })\end{array}$ & $\begin{array}{c}\text { Inhibiton } \\
(\%)\end{array}$ & $\begin{array}{c}\text { Weight of cotton } \\
\text { pellet }^{\#}(\mathrm{mg})(\mathrm{Dried})\end{array}$ & $\begin{array}{c}\text { Inhibiton } \\
(\%)\end{array}$ \\
\hline Control & $2 \mathrm{ml} / \mathrm{kg}$, p.o. & $187.3 \pm 4.0$ & - & $43.1 \pm 1.6$ & - \\
Extract & $1 \%$ Tween 80 & & & & \\
Extract & 100 & $123.5 \pm 2.9$ & 34.0 & $28.5 \pm 1.5$ & 33.9 \\
Indomethacin & 200 & $107.3 \pm 3.7^{*}$ & 42.7 & $21.5 \pm 1.3^{*}$ & 50.1 \\
\hline
\end{tabular}

${ }^{\#}$ Values are mean \pm S.E.M. $(\mathrm{n}=6)$

${ }^{*} p<0.05,{ }^{* *} p<0.01$ compared with control.

Table 3. Effect of MET on acetic acid induced writhing test in mice

\begin{tabular}{cccc}
\hline Treatment & Dose $(\mathrm{mg} / \mathrm{kg})$ & No of writhing & Inhibition $(\%)$ \\
\hline Control & $2 \mathrm{ml} / \mathrm{kg}$, p.o. $1 \%$ Tween 80 & $38.5 \pm 1.6$ & - \\
Indomethacin & 10 & $14.1 \pm 1.0^{* *}$ & 63 \\
Extract & 100 & $26.6 \pm 1.4^{*}$ & 30.75 \\
Extract & 200 & $16.8 \pm 1.3^{* *}$ & 56.28 \\
Extract + Indomethacin & $100+10$ & $10.6 \pm 1.3^{* *}$ & 72.38 \\
Extract + Indomethacin & $200+10$ & $8.4 \pm 1.2^{* *}$ & 78 \\
\hline
\end{tabular}

\footnotetext{
${ }^{\#}$ Values are mean \pm S.E.M. $(\mathrm{n}=6)$
}

${ }^{*} p<0.05,{ }^{* *} p<0.01$ compared with control. 
analgesic effects induced by different doses of MET on the writhing test in mice are shown in Table 3. The MET at the dose of 100 and $200 \mathrm{mg} / \mathrm{kg}$, b.w. and indomethacin $10 \mathrm{mg} / \mathrm{kg}$, b.w. exhibited significant $(p<0.01)$ inhibition of the control writhes at the rate of $30.7,56.2$ and $63.0 \%$, respectively. In synergistic addition, MET + indomethacin at the different doses also potentiated (72.3 and $78.0 \%)$ the indomethacin-treated analgesia (Table 3).

\section{DISCUSSION}

In Indian system of medicine, certain herbs are claimed to provide relief of pain and inflammation. The claimed therapeutic reputation has to be verified in a scientific manner. The methanol extracts of Triphala possess significant anti-inflammatory effect in the acute and sub-acute inflammation in rats. Carrageenan induced acute inflammation in animals is one of the most suitable test procedures to screen anti-inflammatory agents. The development of carrageenan-induced edema is biphasic, the first phase is attributed to the release of histamine, $5-\mathrm{HT}$ and kinins, while second phase is related to the release of prostaglandins (Larsen et al., 1983). The methanol extract or Triphala showed a dose dependent anti-edematogenic effects on paw edema. The results suggest that the main mechanism of action may involve the inhibition of prostaglandin biosynthesis pathway and also influence other mediators of inflammation.

Inflammation is a complex chronic process, cotton pellet-induced granuloma is a typical feature of an established chronic inflammatory reaction and can serve as a subchronic and chronic inflammatory test model for investigation of antiarthritic substances. This model has been employed to assess the transudative and proliferative components of chronic inflammation. The fluid adsorbed by the pellet greatly influences the wet weight of the granuloma whereas the dry weight correlates well with the amount of granulomatous tissue formed. Admininstration of methanol extract of Triphala (100 and $200 \mathrm{mg} / \mathrm{kg}$, b.w.) and indomethacin $(10 \mathrm{mg} / \mathrm{kg}$ b.w.) appear to be effective in inhibiting the wet weight of cotton pellet. On the other hand, the methanol extract of Triphala effect on dry weight of cotton pellet was almost near to that of indomethacin.

In acetic acid induced abdominal writhing which is the visceral pain model, the processor releases arachidonic acid via cyclooxygenase and prostaglandin biosynthesis, and plays a role in the nociceptive mechanisms (Franzotti et al., 2002). Results of the present investigation show that all the doses of the methanolic extract of Triphala produced significant analgesics effect and this effect may be due to inhibition of the synthesis of the arachidonic acid metabolite. In addition, MET potentates the analgesic activity of indomethacin The mechanism of anti-inflammatory action of methanol extracts of Triphala may be due to its anti-oxidant activity of Triphala. Reactive oxygen species (ROS) generated endogenously or exogenously are associated with the pathogenesis of various diseases such as atherosclerosis, diabetes, cancer, arthritis and aging process (Guyton et al., 1997). Inflammation is a complex process and ROS play an important role in the pathogenesis of inflammatory diseases (Conner and Grisham, 1996). Thus, anti-oxidants that scavenges.

ROS are expected to improve these disorders. Triphala has anti-oxidant activity to quench free radicals formed in tissues and this activity may decrease inflammation (Naik et al., 2005). The major bio-active phytopharamceuticals in Triphala are polyphenols such as gallic acid, ellagic acid and epigallocatachin gallate and vitamin C (ascorbic acid) (Hans wohlmuth, 1997). T. chebula fruit (a component of Triphala) has higher phenolic content and stronger in virto lipid per oxidation inhibition capability. (Naik et al., 2005).

The polyphenols and vitamin $\mathrm{C}$ in Triphala might be responsible for anti-inflammatory activity and analgesic activity. E. officinalis (P. emblica), another 
component of Triphala, has anti-inflammatory activity and has high content of vitamin $\mathrm{C}$ and the flavonoid constituent quercetin. Vitamin $\mathrm{C}$ is an antioxidant which efficiently scavenges toxic free radicals and other ROS formed in cell metabolism (Oreste et al., 2002).

The safety of crude alcoholic extracts of Triphala was found to lack cellular toxicity in an assay using fresh sheep erythrocytes (Ahmad et al., 1998). Further studies are in progress to isolate polyphenols of tannins and flavonoids from the methanol extract of Triphala and to correlate their activities with the compounds isolated from E. offcinalis, T. chebula and T. bellerica. The isolated molecules from Triphala will be studied on inflammatory pathway such as lipooxygenase and cyclooxygenase path way.

This study supports the contention that traditional medicines remain a valuable resource in the potential discovery of Phyto pharmaceuticals and lead molecules from medicinal plants. A remarkable anti inflammatory and analgesic activity exhibited by methanolic extract of 'Triphala' provides a scientific validation for the popular use of this drug and helped us in further work on isolation and identification of bio active compounds which influence on the inflammation pathway.

\section{ACKNOWLEDGMENTS}

The authors are grateful to Department of Pharmacology, C.L.Baid Metha College of Pharmacy, Chennai, India, for the constant support and encouragement throughout this study.

\section{REFERENCES}

Ahmad I, Mehmood Z, Mohammad F. (1998) Screening of some Indian medicinal plants for their antimicrobial properties. J. Ethnopharmacol. 62, 183-193.

Anonymous. (1984) Alfred Benzon Symposium Copenhagen on August 1984. In: Farnsworth NR. The role of medicinal plants in drug development, Proceedings of the Natural Products in Drug Development, Denmark.
Brooks PM, Day RO. (1991) Nonsteriodal antiinflammatory drugs: diffrences and similarities. $N$. Eng. J. Med. 3, 241-246.

Conner EM, Grisham MB. (1996) Inflammation, free radicals and antioxidants. Nutrition 12, 271-274.

D'Arcy PF, Haward EM, Muggleton RW, Townsend SB. (1960) The anti-inflammatory action of griseofulvin in experimental animals. J. Pharm. Pharmacol. 12, 659-665.

Dutta BK, Rahman I, Das TK. (1998) Antifungal activity of Indian plant extracts. Mycoses. 41, 535-536.

Franzotti EM, Santos CVF, Rodrigues HMSL, Mourao RHV, Andrade AR, Antoniolli AR. (2002) Antiinflammatory, analagesic and acute toxicity of Sida cardiafolia L. J. Ethnopharmacol. 72, 273-278.

Gulati R, Agarwal S, Agarwal SS. (1995) Hepatoprotective studies on Phyllanthus emblica and quercitin. Indian J. Exp. Biol. 33, 261-268.

Guyton KZ, Gorospe M, Holbrook NJ. (1997) Oxidative stress and the molecular biology of antioxidant defenses, pp.247-272, Cold spring Harbor laboratory press, New York.

Halliwell B, Gutteridge JMC. (1999) Free radicals in biology and medicine, pp.291-294, Oxford University press, Oxford.

Hans wohlmuth. (1997) triphala-a short review: Antioxidant properties of the Ayurvedic formulation triphala. Int. J. Pharmacog. 35, 313-317.

Hashimoto M, Nakajima Y. (1997) Anti-obesity agents, alphaamylase inhibitors, lipase inhibitors, foods and beverages containing plant extracts'. Jpn. Kokai Tokkyo Koho J. 9, 227-398.

Larsen GL, Henson PM. (1983) Mediators of inflammation. Annu. Rev. Immunol. 1, 331-335.

Naik GH, Priyadarsini KI, Bhagirathi RG, Mishra B. (2005) In vitro antioxidant studies and free radical reactions of triphala, an ayurvedic formulation and its constituents. Phytother. Res. 19, 582-586.

Nadkarni AK. (1976) Indian Materia Medica,Vol.1, Popular Press Ltd. Mumbai, India, p.1972.

Oreste Arrigoni, De Tullio MC. (2002) Ascorbic acid: much more than just an antioxidant. Biochi. et. Biophy. Acta, 1569, 1-9.

Rani G, Bala S, Grover IS. (1994) Anti-mutagenic studies of diethyl ether extract and tannin fractions of emblica myroblan (Emblica officinalis) in Ames assay. J. Plant Sci. Res. 10, 1-4. 
Rasool M, Sabina EP. (2007) Anti-inflammatory effect of the Indian Ayurvedic herbal formulation triphala on adjuvant-induced arthritis in mice. Phytother. Res. 21, 889-894.

Sharma RK, Dash B. (1998) Carka Samhita Vol. II. Chowkamba Sanskrit Series Office, Varanasi, India, p156.

Suresh K, Vasudevan DM. (1994) Augmentation of murine natural killer cell and antibody dependent cytotoxicity activities by Phyllanthus emblica, a new immunomodulator. J. Ethanopharmacol. 44, 55-60.

Vane J, Booting R. (1987) Inflammation and the mechanism of action of anti-inflammatory drugs, Faseb J. 1, 85-89.

Valsaraj R, Pushpangadan P, Wagner Smitt U, Adsersen A, Brogger Christensen S, Sittie A, Nyman U, Nielsen C, Olsen CE. (1997) New anti-HIV-1, antimalarial, and antifungal compounds from Terminalia bellerica. J.
Nat. Prod. 60, 739-742.

Trease GE, Evans WC. (1989) Text book of pharamacognosy, Oxford University press. Oxford. p.256.

Takagi N, Sanashiro T. (1996) Health foods containing antioxidative and anti-allergy food materials. Jpn. Kokai Tokkyo Koho J. 10, 65-70.

Tokura K. Kagawa S. (1995) Anticancer agents containing chebulanin from Terminalia chebula. Jpn. Kokai Tokkyo Koho J. 7, 138-165.

Tariq M, Hussain SJ, Asif M, Jahan M. (1977) Protective effect of fruit extracts of Emblica officinalis Gaertn. and Terminalia bellerica Roxb. in experimental myocardial necrosis in rats. Indian J. Exp. Biol. 15, 485-486.

Winter CA, Risley EA, Nuss GW. (1962) Carrageenan induced oedema in hind paw of the rats as an assay for anti-inflammatory drugs. Proc. Soc. Exp. Biol. Med. 111, 544-547. 